\title{
Modern Engineered Materials and Technologies for Metal Forming Applications
}

\author{
Sutasn Thipprakmas, ${ }^{1}$ Man S. Joun, ${ }^{2}$ and Lars-Erik Lindgren ${ }^{3}$ \\ ${ }^{1}$ Department of Tool and Materials Engineering, King Mongkut's University of Technology Thonburi, \\ Bangkok 10140, Thailand \\ ${ }^{2}$ School of Mechanical Engineering, Engineering Research Institute, Gyeongsang National University, No. 501, \\ Jinju-daero, Jinju-si, Gyeongsangnam-do, Republic of Korea \\ ${ }^{3}$ Luleå University of Technology, Luleå, Sweden \\ Correspondence should be addressed to Sutasn Thipprakmas; sutasn.thi@kmutt.ac.th
}

Received 7 November 2016; Accepted 7 November 2016; Published 23 March 2017

Copyright (C) 2017 Sutasn Thipprakmas et al. This is an open access article distributed under the Creative Commons Attribution License, which permits unrestricted use, distribution, and reproduction in any medium, provided the original work is properly cited.

During the last decades the development of modern engineered materials and technologies for metal forming applications to new and existing processes, products, and tool represents an emerging issue both from an industry and from an academic viewpoint. Nowadays, a lot of research activities in the field of metal forming have been accomplished and there are a wide range of applications where the modern engineered materials are used.

The objective of this special issue was to provide a wide spectrum of new information on modern engineered materials and technologies for metal forming applications as well as to provide readers with a representative outlook of the latest achievements in this field. The topics focused on the understanding of the interaction between materials of workpiece and the tool as well as the effect of process parameters and so forth when improving efficiency of process, product quality, and tool life.

This special issue offers a selected and articulated overview of the examined topics. It contains five papers and the details were listed as follows.

Z.-b. Xiao et al. revised the constitutive equation of $2026 \mathrm{Al}$ alloy under hot compression which was done by compensation of temperature considering the impact of the second phase on true stress. It indicated that the revised constitutive equation can give an accurate prediction of the peak stress for $2026 \mathrm{Al}$ alloy and can be used in the hot processing of $2026 \mathrm{Al}$ alloy.
Jindong et al. investigated the cold compression deformation method to reduce the quenching residual stress of 7A85 aluminum alloy thick block forging. It was found that this method has a significant effect on reducing stress if an appropriate amount of compression deformation is chosen. The optimal compression deformation value is about $1 \%$ $2 \%$, reducing $70 \%$ residual stress for 7 A 85 aluminum alloy specimens sized $100 \times 60 \times 40 \mathrm{~mm}$.

Y.-S. Lee et al. in their article titled "Development of a Master Sintering Curve for Al-Mg Alloy," to help an engineer to design pressure assisted sintering process for $\mathrm{Al}-\mathrm{Mg}$ alloy, developed the master sintering curve for Al-Mg alloy which was investigated for suitable design of pressing pressure for this Al-Mg alloy.

O. V. Berezshnaya et al. investigated the thermostressed state of coating formation at electric contact surfacing of "shaft" type parts. It showed that, owing to the increases in friction coefficient, the change of the speed asymmetry factor has a significant influence on the forming of the coating. The nomograms for determination of the stress on the rollerelectrode are illustrated, as well as the finite thickness of the coating as the function of the initial thickness of the compact material and the deformation degree are shown.

P. A. Prates et al. in their article titled "Inverse Strategies for Identifying the Parameters of Constitutive Laws of Metal Sheets" showed a great development of inverse strategies coupled with finite element simulations, namely, in FEMU 
strategies for the identification of parameters of constitutive laws describing the plastic behavior of metal sheets. These strategies should be directed towards the simultaneous identification of parameters of any constitutive law, including isotropic and kinematic hardening, and any anisotropic yield criterion.

\section{Acknowledgments}

The guest editors hope the information provided in this special issue is useful and offers stimulation to the new development of modern engineered materials and technologies for metal forming applications. Finally, we would like to thank the authors for an excellent contribution of their research works and we also very warmly acknowledged the reviewers for an excellent contribution of their valuable review results.

Sutasn Thipprakmas Man S. Joun

Lars-Erik Lindgren 

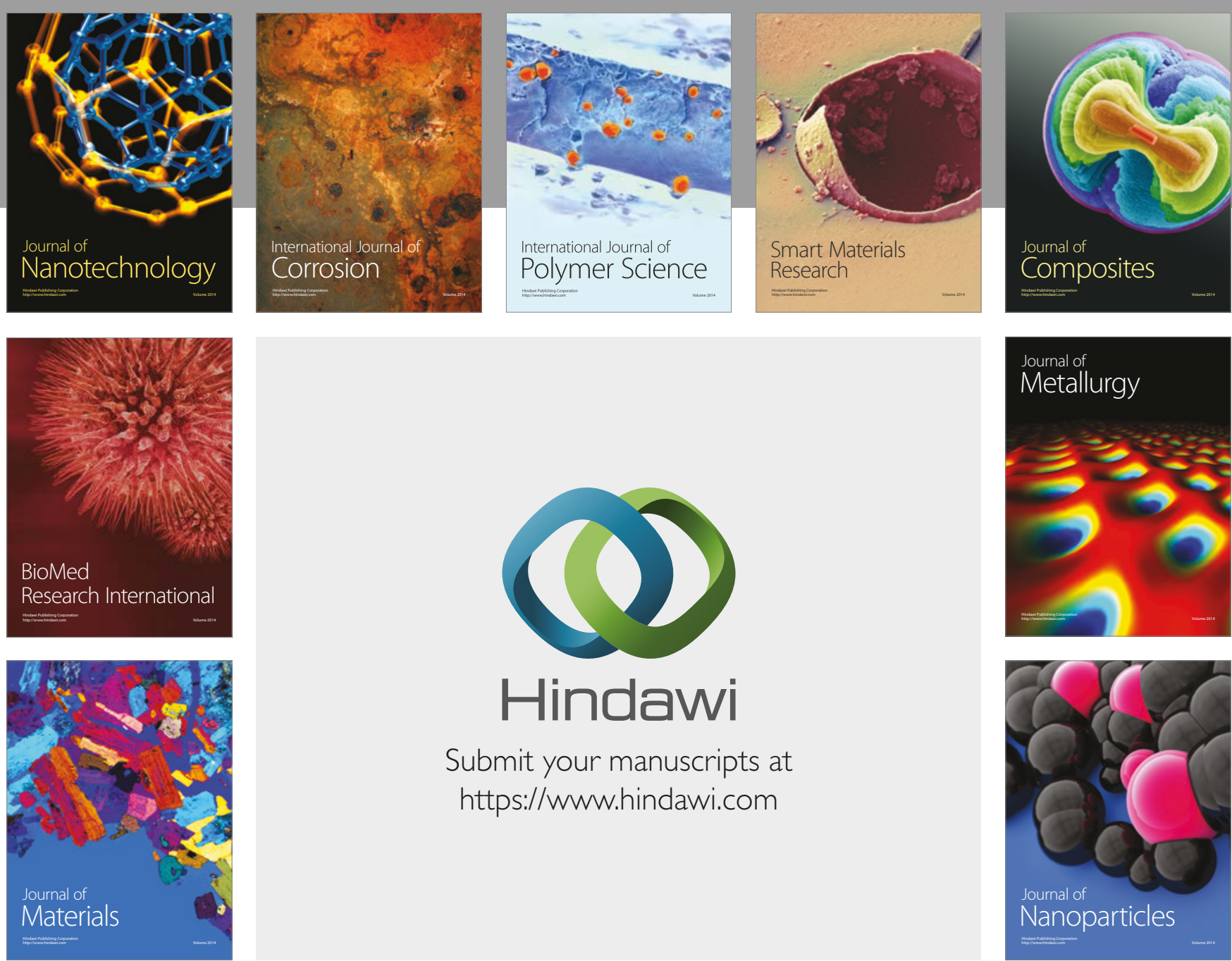

\section{Hindawi}

Submit your manuscripts at

https://www.hindawi.com
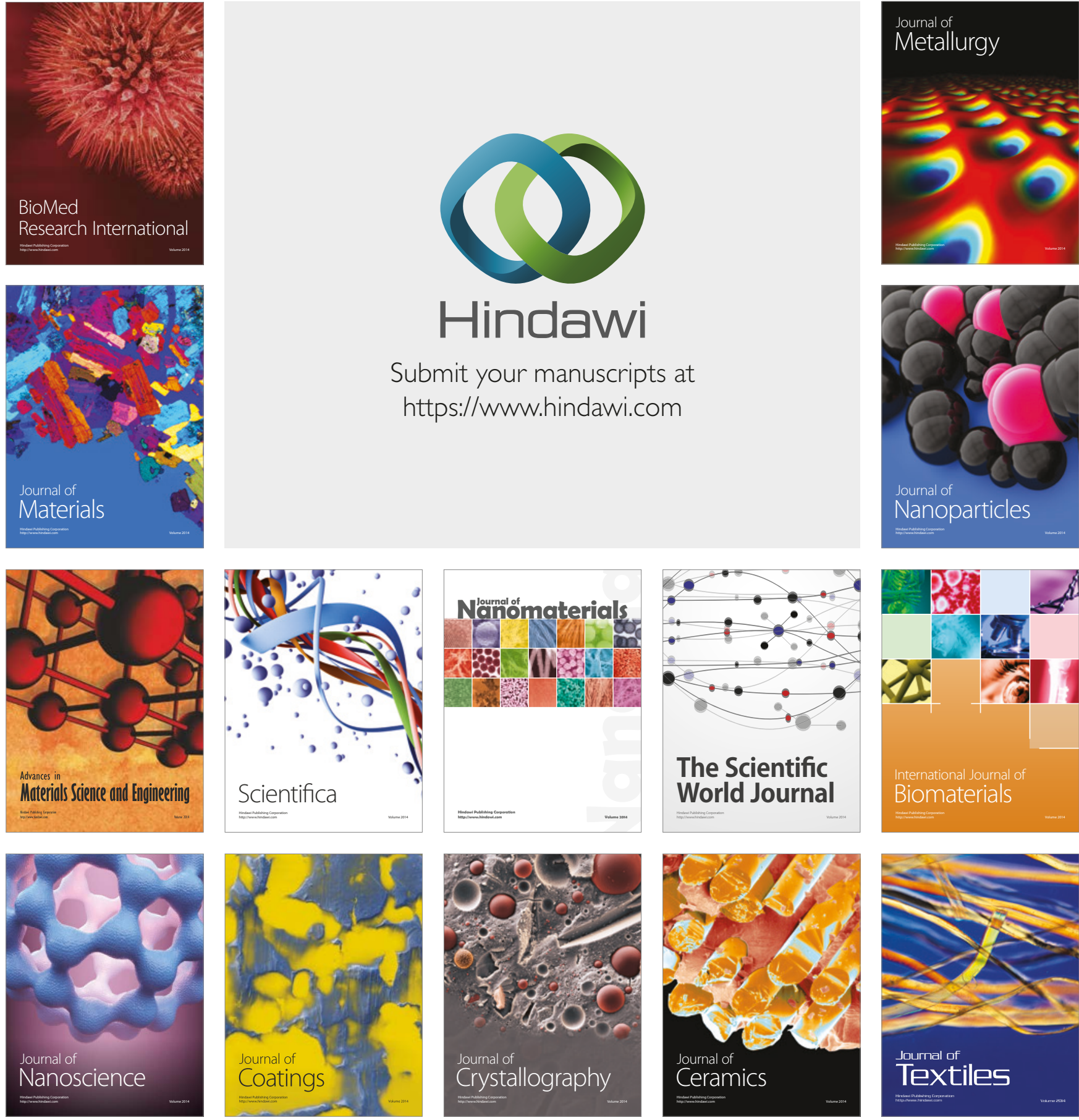

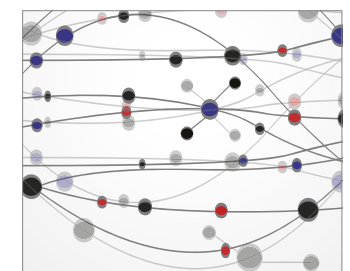

The Scientific World Journal
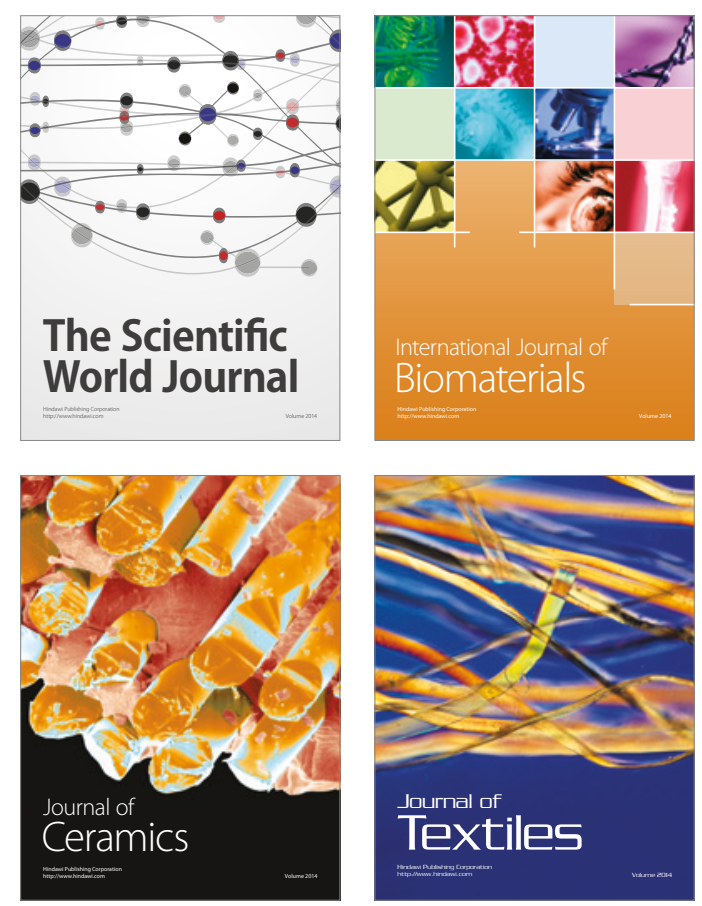